\title{
Gender Difference in the Impact of Examination Stress on Psychological and Physiological Profiles of Dental Students
}

\author{
Surya Goutham Abraham $\mathrm{K}^{1}$, Sridevi $\mathrm{G}^{2}$, PremaSembulingam ${ }^{3 *}$ \\ ${ }^{I}$ Dental student, Sathyabama University Dental College \& Hospital, Jeppiar Nagar,Rajiv Gandhi Salai, OMR, \\ Chennai - 600 119.Tamil Nadu \\ ${ }^{2}$ Lecturer, Department of Physiology, Sathyabama University Dental College \& Hospital, Jeppiar Nagar, Rajiv \\ Gandhi Salai, OMR, Chennai-600 119.Tamil Nadu \\ ${ }^{3}$ Professor of Physiology and Head of $R \& D$ [Retired], Madha Medical College \&Research Institute, \\ Kundrathur Main Road, Thandalam, Kovur, Chennai - 600 122, Tamil Nadu.
}

\begin{abstract}
The stress impactduring preparatory,examination and post-examination periodson psychophysiological parameters in 40 normal male and female dental students was studied and the gender difference was explored. The stress level was assessed using Perceived Stress Scale (PSS);psychological changes were assessed by determining short term and long term memory (STM, (LTM)) using RAVLT Word List A and B Subsections and physiological changes were determined by recordingsystolic blood pressure (SBP), diastolic blood pressure (DBP), heart rate (HR) and heart rate variation (30:15 ratio). The results revealed that perceived stressdecreased significantly in post-exam period inboth the genders ( $p<0.0001)$ than in preparatory period. STM and LTM did not show any significant change in both the genders. SBP was not altered significantly in exam and post-exams periods compared to that of preparatory period in males and it increased significantly in exam period( $p<0.015)$ in females.DBP decreased more significantly in males and less significantly in females after exams $(p<0.008,0.028)$ ). HR decreased significantly after exams in both the genders compared to that of preparatory period $(p<0.0007,0.0001)$. 30:15 ratiodecreasedmore significantly in males and less significantly in females during exams ( $p<0.0001,0.008)$. Thus, theexamination stress affects the psycho-physiological variables in both genders and the effect was equal in both the genders with elevated sympathetic activity. Counseling, yoga and meditation may be useful in combating these stress effects and prevent the future complications
\end{abstract}

Keywords: Autonomic functions, Examination stress, Long term memory,Perceived stress scale, Short term memory,

\section{Introduction}

Professional courses are stressful to the student community because of the new curriculum that is entirely different from the high school curricula and other educational courses. It is more pronounced among the first year students in professional institutions because of the competition and expectations from the administrators of the institutions, academic staff and the parents. Apart from all these stressors in professional courses, the examination stress stands at the top. It is a feeling of an anticipation, apprehension and anxiety created by the thought, approaching date and doubtful fear of the performance in examination.

The students in the dental course are no way different from the students of other professional courses like medical, engineering, agriculture etc. Though moderate amount of stress is essential for maintaining and progressing in their day-to-day performance and for facing the examinations with confident, multiplied and cumulative stress can be harmful to body and the mind.

After all, what is stress? The term "stress" was first introduced by Hans Selye in 1936 and in his words, stress is "the non-specific response of the body to any demand for change" [1]. Stress is known to be associated with autonomic related neurobehavioral and cardiovascular changes [2].An attempt had been made in this study to probe the consequences of exposure to examination stress on the first year BDS students.

In response to a threat of any kind, our body is armored with the protective mechanism through neural and hormonal systems. Neural part is operated through autonomic nervous system (ANS) and the hormonal part functions through pituitary and adrenal axis. These two functionsare coordinated as Hypothalamic Pituitary Adrenal (HPA) axis. ANS provides quick and short response in the form of "fight-or-flight" nature that makes the body to withstand the stress whereas HPA axis provides slower and prolonged response with sufficient resources that areneeded to withstand the stress [3]. Thus, the objective of this study was to evaluate the impact of examination stress with sleep deprivation on psycho-physiological parameters in the $1^{\text {st }}$ year BDS students and to compare the impact of gender difference in this respect. 


\section{Materials And Methods}

Normal young and healthy male and female students (20 each) with the anthropometrically matched variables were chosen for this study from Sathyabama Dental College and Hospital, Jeppiaar Nagar, Rajiv Gandhi Road, Chennai. The Intuitional human ethical committee has given ethical clearance for the present study as it does not involve invasive procedures. After explaining the experimental procedure and making the subjects fully aware of their role in the project, informed consent was obtained from them. Students with known cardiovascular problems, sleep disorder problem, neurological problems or those who were under medication for some reason or other were excluded from the study.

The students were assessed under three different conditions:

1. Pre-examination period (preparatory period)

2. Examination period (after the commencement of exam schedule)

3. Post examination period (within 3 days after the completion of all examinations).

The subjects were assessed for

1. the level of perceived stress

2. psycho - physiological changes in the form of

a. short term memory

b. long term memory

3. functional status of ANS

\subsection{Assessment of Perceived stress}

Perceived stress was assessed by using Perceived Stress Scale 10 (PSS-10). It is a 10-item questionnaire as shown in Appendix A[4]. Higher scores correspond to greater global stress. The questions in this scale were pertaining to the feelings and thoughts of the participants in the last one month. In each case, he/she was asked to indicate by circling how often he/she felt or thought a certain way. Scoring was done as $0=$ Never. 1 = Almost Never. 2 = Sometimes. $3=$ Fairly Often. 4 = Very Often.

\subsection{Psycho-physiologicalchanges}

\subsubsection{Short term memory task}

Short-term memory (STM) was assessed by displaying random pairs of letters on the screen using Power Point for three seconds and participants were then given ten seconds to recall from each trial. The slides were automatically timed for accurate measurement of elapsed time. There were six random trials in total, and each trial was increased in difficulty.The first trial consisted of two letters, the second with four letters, third with six letters, fourth with seven letters, fifth with eight letters, and the last trial had nine letters.These letters were randomly selected to avoid chunking and the possibility of creating words. Since this study tested the participants during two occasions with three weeks in between, the same letters were presented in both the sessions (Appendix B) [5].

Appendix A-PSS 10

\begin{tabular}{|c|c|}
\hline $\begin{array}{l}\text { 1. In the last month, how often have you been upset because of something that happened } \\
\text { unexpectedly? }\end{array}$ & $\begin{array}{lllll}0 & 1 & 2 & 3 & 4\end{array}$ \\
\hline $\begin{array}{l}\text { 2. In the last month, how often have you felt that you were unable to control the important } \\
\text { things in your life? }\end{array}$ & $\begin{array}{lllll}0 & 1 & 2 & 3 & 4\end{array}$ \\
\hline In the last month, how often have you felt nervous and "stressed"? & $\begin{array}{lllll}0 & 1 & 2 & 3 & 4\end{array}$ \\
\hline $\begin{array}{l}\text { 4. In the last month, how often have you felt confident about your ability to handle your } \\
\text { personal problems? }\end{array}$ & $\begin{array}{lllll}0 & 1 & 2 & 3 & 4\end{array}$ \\
\hline In the last month, how often have you felt that things were going your way? & $\begin{array}{lllll}0 & 1 & 2 & 3 & 4\end{array}$ \\
\hline $\begin{array}{l}\text { 6. In the last month, how often have you found that you could not cope with all the things } \\
\text { that you had to do? }\end{array}$ & $\begin{array}{lllll}0 & 1 & 2 & 3 & 4\end{array}$ \\
\hline 7. In the last month, how often have you been able to control irritations in your life? & $0 \begin{array}{llll}0 & 1 & 2 & 4\end{array}$ \\
\hline 8. In the last month, how often have you felt that you were on top of things? & $\begin{array}{lllll}0 & 1 & 2 & 3 & 4\end{array}$ \\
\hline $\begin{array}{l}\text { 9. In the last month, how often have you been angered because of things that were outside } \\
\text { of your control? }\end{array}$ & $\begin{array}{lllll}0 & 1 & 2 & 3 & 4\end{array}$ \\
\hline $\begin{array}{l}\text { 10. In the last month, how often have you felt difficulties were piling up so high that you } \\
\text { could not overcome them? }\end{array}$ & $\begin{array}{lllll}0 & 123 & 4\end{array}$ \\
\hline
\end{tabular}


Gender Difference in the Impact of Examination Stress on Psychological and Physiological Profiles..

Short term memory assessment

Instructions for the Short term memory Assessment

Following instruction was given to the participants: "You are about to do a STM test. A few letters will flash on your computer monitor for 3 seconds. Your job is to write down as many letters as you can remember after they disappear." (Appendix B)

\begin{tabular}{|c|c|c|c|c|c|}
\hline Trial 1 & Trial 2 & Trial 3 & Trial 4 & Trial 5 & Trial 6 \\
\hline U M & T Z L N & A J P W B D & H B X U P R L & K M Y O S G E F & L R W H K B C Q T \\
\hline
\end{tabular}

Participants were exposed to these letters for three seconds, followed by ten seconds for free recall.

\subsubsection{Long-Term Memory Task}

The following instructions were given before they started the Long-Term Memory (LTM) Assessment: "Fifteen words will be presented for 30 seconds. Once this is completed, you will be asked to complete a letter assessment. In the end, you will be asked to recall as many words as you can remember from this list"

To testLTM, participants were exposed to fifteen words for thirty seconds during the beginning of the experiment (Appendix C). The word lists for each session were selected from the RAVLT Word List A and B Subsection [6]. Here, it was operationally defined to test LTM as a process which required a delay period after an hour.After all these tasks that took about an hour, participants were asked to write down as many words as they could remember. Since the study tested participants on two different occasions, different words were displayed during each testing sessions with identical procedures and the word lists were counterbalanced. The new words were also taken from the RAVLT World List section. (Appendix D for Long-Term Memory Test). The word groups were validated for difficulty and consistency from one testing session to another. These lists were counterbalanced from baseline to the examination period in order to avoid any carry-on effects.

Appendix-C and D: Long term memory assessment.

RAVLT Word List A

\begin{tabular}{|c|c|c|c|c|}
\hline Desk & Fish & Ranger & Glasses & Mountain \\
\hline Boat & Bird & Church & Gun & Cloud \\
\hline Pencil & Shoe & Lamb & Towel & Stove \\
\hline
\end{tabular}

\begin{tabular}{|c|c|c|c|c|}
\hline Coffee & Moon & Garden & Nose & Color \\
\hline House & Drum & River & Bell & Curtain \\
\hline Hat & School & Farmer & Turkey & Parent \\
\hline
\end{tabular}

\section{Autonomic function tests}

The functional status of autonomic nervous system (ANS) was evaluated by simple bed side tests postulated by Ewing and Clarkes and adapted by PremaSembulingam et al [7].These tests are mainly based on the cardiovascular reflexes. The variables chosen were systolic blood pressure (SBP) and diastolic blood pressure (DBP) that reflect the functional status of sympathetic nervous system (SNS) and heart rate (HR) and heart rate variability (HRV) in the form of 30:15 ratio that reflect the functional status of parasympathetic nervous system (PNS)

SBP, DBP and HR were recorded by using fully automated BP apparatus (OMRON) in the supine position. For HRV, Electrocardiogram (ECG) was recorded continuously in Lead II by using three channel Student Physiograph in lying posture (10 waves), while getting up and after standing (60 waves). HRV was calculated as 30:15 ratio, ie., as the longest R-R interval at around $30^{\text {th }}$ beat divided by the shortest R-R interval at around $15^{\text {th }}$ beat after standing. These recordings were done after short term and long term memory tasks.

\section{Statistical Analysis}

Data were entered in Excel spread sheet and were analyzed using Students' 't'test.

\section{Results}

\subsection{Effect of examination stress on psycho-physiological variables}

PSS: In males, PSS was very high in pre-examination period $(22.10 \pm 0.47)$. It declined slightly during examination period (20.15 \pm 15 , non-significant). But in post-examination period, it declined significantly $(10.90 \pm 0.69, \mathrm{p}<0.0001)$ compared to that of pre-examination period (Table 1).In females also, PSS wasvery high in pre-examination period $(26.15 \pm 0.51)$ and it was reduced to $21.40 \pm 0.49$ in examination period (nonsignificant). It decreased furtherin post-examination period $(12.25 \pm 0.61)$ and this decrease was statistically significant compared to that of pre-examination period( $p<0.0001)$ (Table 2).However, between males and females, there was no significant difference in response to the perceived stress in all the three phases.(Table 3).

STM and LTM: Both males and females did not showsignificant differencein STM and LTM in all the three periods. Between the genders also, there was no significant difference in STM and LTM in all the three phases (Table 1, Table 2 and Table 3). 
Gender Difference in the Impact of Examination Stress on Psychological and Physiological Profiles..

Table 1.Effect of Examination Stress on Psycho-physiological functions in male and females

\begin{tabular}{|c|c|c|c|c|c|c|c|}
\hline Variables & Gender & $\begin{array}{c}1 . \\
\text { Pre- } \\
\text { examperiod }\end{array}$ & $\begin{array}{c}2 . \\
\text { Exam- } \\
\text { period }\end{array}$ & $\begin{array}{c}3 . \\
\text { Dif. } \\
\text { between } \\
1 \& ?\end{array}$ & $\begin{array}{l}4 . \\
\text { Post- } \\
\text { exam } \\
\text { narind }\end{array}$ & $\begin{array}{c}5 . \\
\text { Dif. } \\
\text { between } \\
1 \& 1\end{array}$ & $\begin{array}{l}\text { Sig }(p<) \\
\text { Between } \\
\quad 3 \& 5\end{array}$ \\
\hline \multirow{2}{*}{ PSS } & Males & $22.10 \pm 0.47$ & $\begin{array}{c}20.15 \pm \\
0.48\end{array}$ & $\begin{array}{c}1.95 \pm \\
0.69\end{array}$ & $\begin{array}{l}10.90 \\
\pm 0.69\end{array}$ & $\begin{array}{l}11.20 \\
\pm 0.86\end{array}$ & 0.0001* \\
\hline & Females & $26.15 \pm 0.51$ & $\begin{array}{c}21.40 \pm \\
0.49\end{array}$ & $\begin{array}{c}4.75 \pm \\
0.78\end{array}$ & $\begin{array}{c}12.25 \pm \\
0.61\end{array}$ & $\begin{array}{c}13.90 \pm \\
0.66\end{array}$ & 0.0001* \\
\hline \multirow{2}{*}{ STM } & Males & $32.85 \pm 0.48$ & $\begin{array}{c}33.65 \pm \\
0.39\end{array}$ & $\begin{array}{c}-0.80 \pm \\
0.65\end{array}$ & $\begin{array}{c}32.90 \pm \\
0.56\end{array}$ & $\begin{array}{c}--0.05 \pm \\
0.79\end{array}$ & 0.921 \\
\hline & Females & $34.45 \pm 0 . .32$ & $\begin{array}{c}35.00 \pm \\
0.29\end{array}$ & $\begin{array}{c}1.88 \pm \\
0.42\end{array}$ & $\begin{array}{c}34.25 \pm \\
0.34\end{array}$ & $\begin{array}{c}1.96 \pm \\
0.44\end{array}$ & 0.966 \\
\hline LTM & Males & $8.39 \pm 0.40$ & $\begin{array}{c}10.38 \pm \\
0.46\end{array}$ & $\begin{array}{c}-2.00 \pm \\
0.64\end{array}$ & $\begin{array}{c}9.24 \pm \\
0.48\end{array}$ & $\begin{array}{c}-0.86 \pm \\
0.56\end{array}$ & 0.895 \\
\hline
\end{tabular}

Values are expressed as mean \pm SEM. PSS - Perceived stress scale. STM - Short term memory LTM - Long term memory Dif - difference Sig - significance Significance level was fixed as $\mathrm{p}<0.05$.

\subsection{Effect of examination stress on autonomic functions}

Systolic blood pressure:In males, SBP did not show any significant change either during examination period or post-examination period compared to that of pre-examination period (Table 1). In females, SBP was higherin examination period $(129.20 \pm 1.81)$ and lowerin post-examination period $(112.60 \pm 2.12)$ than that of pre-examination period $(117.00 \pm 2.08)$ and the level of increase during examination period was significantly more $(\mathrm{p}<0.015)$ than the levelof decrease during post-examination period (Table 1 and 2). Between the genders, males and females did not show any significant difference between pre-examination and examination periods. But in post examination period, the reduction in SBP was significantly more in females than in males ( $p$ $<0.002$ ) (Table 3).

Diastolic blood pressure: In males, DBP increased $(80.20 \pm 0.75)$ during examination period and decreased after examination period $(72.90 \pm 0.84)$ compared to that of preparatory period $(77.50 \pm 1.09)$. The level of decrease was more $(4.60 \pm 1.49)$ than the level of increase $(-2.70 \pm 0.69)$ with statistical significance $(\mathrm{p}<$ 0.008 ) (Table 1). In females also DBP increased $(83.40 \pm 0.85)$ during examination period and decreased after examination period $(82.40 \pm 0.79)$ compared to that of preparatory period $(70.50 \pm 0.81)$ and the level of decrease was more $(11.70 \pm 0.09)$ with statistical significance $(\mathrm{p}<0.028)$ than the level of increase $(-1.00 \pm$ 0.41) (Table 2). Between the genders, males showed slightly lower value during preparatory and examination period and higher valueafter examination period than the females: however, they were not statistically significant (Table 3)

Heart rate: In males, HR did not show any significant change during examination period $(84.4 \pm 0.84)$ and was reduced(74.35 \pm 0.70$)$ significantly $(\mathrm{p}<0.0007)$ after examination period,compared to that of preparatory period $(84.20 \pm 1.16)$ (Table 1$)$. In females also HR did not show any statistically significant change between preparatory period $(80.25 \pm 1.30)$ and examination period $(81.90 \pm 0.91)$ but reduced significantly $(73.90 \pm 0.66)(\mathrm{p}<0.0001)$ after examinations compared to that of preparatory period (Table2). Between the genders, HR was slightly more in males than in females in all the three phases but the difference was not significant (Table 3).

Heart rate variation: In males, 30:15 ratio decreased non-significantly $(1.38 \pm 0.02)$ during examination period and increased significantly after examination period $(1.63 \pm 0.16)(\mathrm{p}<0.0001)$ compared to that of preparatory period $(1.53 \pm 0.20)$ (Table 1$)$.In females also 30:15 ratio decreased $(1.04 \pm 0.02)$ during examination period and increased $(1.29 \pm 0.02)$ after examination period compared to that of preparatory period $(1.24 \pm 0.02)$. But the decrease during examination was more and statistically significant $(\mathrm{p}<0.008)$ than the 
Gender Difference in the Impact of Examination Stress on Psychological and Physiological Profiles..

increase after examination period (Tabl2 2). Between the genders, females showed significantly lesser values ( $\mathrm{p}$ $<0.000)$ in all the three phases compared to that of males(Table 3).

\begin{tabular}{|c|c|c|c|c|c|c|c|}
\hline Variables & Gender & $\begin{array}{c}1 \\
\text { Pre-exam } \\
\text { period }\end{array}$ & $\begin{array}{c}2 . \\
\text { Exam } \\
\text { period }\end{array}$ & $\begin{array}{c}3 \\
\text { Dif. } \\
\text { between } \\
1 \& 2\end{array}$ & $\begin{array}{c}4 \\
\text { Post-exam } \\
\text { period }\end{array}$ & $\begin{array}{c}5 \\
\text { Dif. } \\
\text { between } \\
1 \& 4\end{array}$ & $\begin{array}{c}\text { Sig }(\mathrm{p}<) \\
\text { Between } \\
3 \& 5\end{array}$ \\
\hline \multirow{2}{*}{$\begin{array}{c}\mathrm{SBP} \\
(\mathrm{mmHg})\end{array}$} & Males & $\begin{array}{c}125.20 \pm \\
1.86\end{array}$ & $\begin{array}{c}125.40 \pm \\
2.13\end{array}$ & $\begin{array}{c}-0.20 \pm \\
2.11\end{array}$ & $\begin{array}{c}124.40 \pm \\
1.34\end{array}$ & $\begin{array}{c}0.80 \pm \\
2.40\end{array}$ & 0.474 \\
\hline & Females & $\begin{array}{c}117.00 \pm \\
2.08\end{array}$ & $\begin{array}{c}129.20 \pm \\
1.81\end{array}$ & $\begin{array}{c}-12.20 \pm \\
2.28\end{array}$ & $\begin{array}{c}112.60 \pm \\
2.12\end{array}$ & $\begin{array}{c}4.40 \pm \\
3.04\end{array}$ & $0.015^{*}$ \\
\hline \multirow{2}{*}{$\begin{array}{c}\text { DBP } \\
(\mathrm{mmHg})\end{array}$} & Males & $77.50 \pm 1.09$ & $\begin{array}{c}80.20 \pm \\
0.75\end{array}$ & $\begin{array}{c}-2.70 \pm \\
0.69\end{array}$ & $\begin{array}{c}72.90 \pm \\
0.84\end{array}$ & $\begin{array}{c}4.60 \pm \\
1.49\end{array}$ & $0.008^{*}$ \\
\hline & Females & $82.40 \pm 0.79$ & $\begin{array}{c}83.40 \pm \\
0.85\end{array}$ & $\begin{array}{c}-1.00 \pm \\
0.41\end{array}$ & $\begin{array}{c}70.70 \pm \\
0.81\end{array}$ & $\begin{array}{l}11.70 \\
\pm 0.79\end{array}$ & $0.028 *$ \\
\hline \multirow{2}{*}{$\begin{array}{c}\text { HR } \\
\text { (Beats/min) }\end{array}$} & Males & $84.20 \pm 1.16$ & $\begin{array}{c}84.4 \pm \\
0.84\end{array}$ & $\begin{array}{c}-0.20 \pm \\
1.00\end{array}$ & $\begin{array}{c}74.35 \pm \\
0.70\end{array}$ & $\begin{array}{c}9.85 \pm \\
1.55\end{array}$ & $0.0007^{*}$ \\
\hline & Females & $80.25 \pm 1.30$ & $\begin{array}{c}81.90 \pm \\
0.91\end{array}$ & $\begin{array}{c}-1.65 \pm \\
1.22\end{array}$ & $\begin{array}{c}73.90 \pm \\
0.66\end{array}$ & $\begin{array}{c}6.35 \pm \\
1.21\end{array}$ & 0.0001 * \\
\hline \multirow{2}{*}{$30: 15$ ratio } & Males & $1.53 \pm 0.20$ & $\begin{array}{c}1.38 \pm \\
0.02\end{array}$ & $\begin{array}{c}0.15 \pm \\
0.01\end{array}$ & $1.63 \pm 0.16$ & $\begin{array}{r}-0.09 \\
\pm 0.02\end{array}$ & $0.0001^{*}$ \\
\hline & Females & $1.24 \pm 0.02$ & $\begin{array}{c}1.04 \pm \\
0.02\end{array}$ & $\begin{array}{c}0.21 \pm \\
0.02\end{array}$ & $1.29 \pm 0.02$ & $\begin{array}{l}-0.05 \\
\pm 0.02\end{array}$ & $0.008 *$ \\
\hline
\end{tabular}

Table 2.Effect of Examination Stress on autonomic functions in male and females Values are expressed as mean \pm SEM. SBP - Systolic blood pressure DBP - Diastolic blood pressure $\mathrm{HR}$ - Heart rate $\mathrm{HRV}-$ Heart rate variability. The significance level was fixed at $\mathrm{p}<0.05$

Table 3. Gender difference in the effect of examination stress on Psycho-physiological functions

\begin{tabular}{|c|c|c|c|c|c|}
\hline Variable & Time of recording & Male & Female & Difference & Sig $(\mathrm{p}<)$ \\
\hline \multirow{3}{*}{ PSS } & Pre-exam period & $22.1 \pm 0.48$ & $26.15 \pm 0.51$ & $-4.05 \pm 0.66$ & 0.313 \\
\cline { 2 - 6 } & Exam period & $20.15 \pm 0.47$ & $21.4 \pm 0.49$ & $-1.25 \pm 0.57$ & 0.941 \\
\cline { 2 - 6 } & Post exam period & $10.9 \pm 0.69$ & $12.25 \pm 0.61$ & $-1.35 \pm 0.70$ & 0.881 \\
\hline \multirow{3}{*}{ STM } & Pre-exam period & $32.85 \pm 0.48$ & $34.45 \pm 0.32$ & $-1.6 \pm 0.47$ & 0.993 \\
\cline { 2 - 6 } & Exam period & $33.65 \pm 0.39$ & $35.00 \pm 0.29$ & $-1.35 \pm 0.51$ & 0.994 \\
\cline { 2 - 6 } & Post exam period & $32.9 \pm 0.58$ & $34.25 \pm 0.34$ & $-1.35 \pm 0.76$ & 0.960 \\
\hline \multirow{3}{*}{ LTM } & Pre-exam period & $8.35 \pm 0.42$ & $8.4 \pm 0.30$ & $-0.05 \pm 0.47$ & 0.362 \\
\cline { 2 - 6 } & Exam period & $10.5 \pm 0.42$ & $10.9 \pm 0.44$ & $-0.4 \pm 0.61$ & 0.598 \\
\cline { 2 - 6 } & Post exam period & $9.3 \pm 0.51$ & $9.7 \pm 0.48$ & $-0.4 \pm 0.67$ & 0.575 \\
\hline
\end{tabular}


Gender Difference in the Impact of Examination Stress on Psychological and Physiological Profiles..

Table 4. Gender difference in the effect of examination stress on Autonomic functions

\begin{tabular}{|c|c|c|c|c|c|}
\hline Variable & Time of recording & Male & Female & Difference & Sig $(\mathrm{p}<)$ \\
\hline \multirow{4}{*}{ SBP } & Pre-exam period & $125.20 \pm 1.86$ & $117.00 \pm 2.08$ & $8.20 \pm 2.22$ & 0.996 \\
\cline { 2 - 6 } & Exam period & $125.40 \pm 2.31$ & $129.20 \pm 1.81$ & $-3.80 \pm 3.26$ & 0.841 \\
\cline { 2 - 6 } & Post exam period & $124.40 \pm 1.34$ & $112.60 \pm 2.12$ & $11.8 \pm 2.80$ & $0.002^{*}$ \\
\hline \multirow{4}{*}{ DBP } & Pre-exam period & $77.50 \pm 1.09$ & $82.40 \pm 0.79$ & $-4.90 \pm 1.63$ & 0.999 \\
\cline { 2 - 6 } & Exam period & $80.20 \pm 0.75$ & $83.40 \pm 0.85$ & $-3.20 \pm 1.34$ & 0.994 \\
\cline { 2 - 6 } & Post exam period & $72.90 \pm 0.84$ & $70.70 \pm 0.81$ & $2.20 \pm 1.02$ & 0.948 \\
\hline \multirow{4}{*}{ HR } & Pre-exam period & $84.20 \pm 1.16$ & $80.25 \pm 1.30$ & $3.95 \pm 1.47$ & 0.977 \\
\cline { 2 - 6 } & Exam period & $84.40 \pm 0.84$ & $81.90 \pm 0.91$ & $2.50 \pm 1.03$ & 0.959 \\
\cline { 2 - 6 } & Post exam period & $74.35 \pm 0.70$ & $73.90 \pm 0.66$ & $0.45 \pm 0.93$ & 0.524 \\
\hline \multirow{3}{*}{$\begin{array}{c}30: 15 \\
\text { ratio }\end{array}$} & Pre-exam period & $1.53 \pm 0.02$ & $1.24 \pm 0.02$ & $0.31 \pm 0.03$ & $0.000^{*}$ \\
\cline { 2 - 6 } & Exam period & $1.38 \pm 0.02$ & $1.04 \pm 0.02$ & $0.34 \pm 0.03$ & $0.000^{*}$ \\
\cline { 2 - 6 } & Post exam period & $1.63 \pm 0.02$ & $1.29 \pm 0.02$ & $0.34 \pm 0.02$ & $0.000^{*}$ \\
\hline
\end{tabular}

\section{Discussion}

It is a known fact that examination is a stressful event and its impact depends on the individual'scapacity inperceivingand reacting toit. Generally we find two categories of students as far as perception of stress is concerned: one category is a group of students who take examinations as a challenge or/and fun with less impact of stress and the other category is the group of students who takeexaminationsas a burden or/and a pressure with more impact of stress. In both the categories, the triggering pointsare the same, ie., necessity of remembering and recalling a large volume of information for facing the examinations,anticipation and uncertainty of the examination results andanguish and anxiety of parental care. The main difference is the fact that first category knows how to manage it with proper approach and methodology and the second category does not know or does not attempt to know how to manage the situation.

Previous reports claim that students in the medical courses - be it MBBS or BDS - are more stressed due to the exposure to a professional coursefor the first time with lot of expectations from the self, parents and the teachers,large volume anddifferent pattern of studies and the novel method of examinations. This is felt more in the initial stages and during the $1^{\text {st }}$ term credit examinations which may affect the students psychologically and physiologically. Thatmade us to venture into the study of the effect of examination stress on the students.

Our results show that stress level was high in both males and females during preparatory period and examination period but declined after the examination period as revealed by PSS. And there was no gender difference in this type of response. The main cause for increased stress level is attributed to the release of cortisol (stress marker) through the increasedactivity of hypothalamo-pituitary adrenal axis (HPA) [8, 9]. This is supported by the reports of Rachit M Joshi et al who observed increased cortisol level in male students of $1^{\text {st }}$ year medical course during the pre-examination period compared to that of post-examination period [10].McEwen and Sapolsky also showed that examinationsinducedmild to moderate stress and there was an increase incortisol secretion: they also suggested that prolonged and intensestress might increase the secretion of catecholamine also along with cortisol which would multiply the stress responses several folds [11].

As far as memory is concerned, our results show that the STM as well as LTM were not affected by the examination stress. Memory is a higher intellectual function involving hippocampus, Papez circuit and cerebral cortex (frontal lobe and parietal lobes). STM develops due to the formation of new neuronal circuits and facilitation of synaptic transmission whereas LTM is due to the consolidation and encoding of memory by constant reinforcement [12]. These types of memorieswould have been developed already in the students due to listening in the classes and repeated reading of the subjects. So, the examination stress might nothave an impact on the already existing memory in our study subjects.

The autonomic functional changes in the present study are quite interesting. SBP was slightly highin males in all the three phases (pre exam, during exam and post exam). But in females it was elevated during exam period (not significant) and declined significantly in post exam period. It shows that cardiovascular reactivity to stress is more in females than in males and it is attributed to the underlying SNS activity. The DBP showed significant increase in exam period and decreased significantly in post exam period compared to preexam periodin both the genders. According to Martin B, stress acts directly or indirectly upon brain stem 
producing an increased sympathetic discharge at spinal level (13). Velasco et al stated that the release of norepinephrine is the main reason for these changes, especially the increased DBP, which causes arteriolar vasoconstriction that raises the peripheral resistance (the main cause for increased DBP) $[14,15]$.

The present study found the peak of heart rate at the pre examination period followed by its decline in exam period and post exam period. This is in accordance with the previous studies by Elwess et al 2005 which showed a similar trend in heart rate during examination stress. Heart rate is proved to be a good indicator of stress faced by students in classroom and laboratory activities, such as oral reports, exams, and laboratory exercises [14]. This increase in HR and blood pressure is an important sympatho-adrenalresponse to physiological stressful experience faced by students during their examination period $[11,15]$.

The 30:15 ratio in the present study depicts a different picture. The elevated 30:15 ratio in males in all the three periods indicates the higher sympathetic activity. According to Convertio, male-female difference in sympathetic discharge may be the reason for this: in males lower limbs get more sympathetic discharge and in females, upper limbs get more sympathetic discharge and so the 30:15 ratio may be more in males [16]. But Jones et al are of the opinion that the male-female difference in the body-fat distribution may be the reason for the difference in the sympathetic activity between the genders: in male type of fat distribution, sympathetic activity was more than the female type of fat distribution[17]

Thus, on the whole the autonomic functions are exaggerated by the examination stress and the students and teachers should bemade aware of the negative consequences of stressfaced during their examination and an efficient relaxation program as well as counselling services can be given to suchstressed students to enhance their academicperformance.

\section{Conclusion}

Thus we conclude that examination is really a stressful experience for the students and both male and female students are equally affected. Our study will throw light on examination related stress of the students' population prone to go for unhealthy coping strategies. So that it can create opportunities for staffs as well as parameters their wards and find their problems in time and adapt preventive coping strategies to manage stress and increase their academic performance and improve their health and wellbeing. Also the education system needs to be reformed withbetter evaluation techniquesin examinations that may cause only a minimum distress in students. Admittedly, the number of study subjects is less and that may be the reason for non-significant values in some areas. These may be rectified by further study in the same line with more number of subjects.

\section{Acknowledgement}

This study was a "Student's short term research project" under ICMR in the Year 2011. We are thankful to ICMR for sponsoring our undergraduate project. Our thanks are due to Sathyabama University Dental College for permitting us to apply for the scheme and encouraging us to complete it successfully.

[1]. http:// www. stress.org/what-is-stress/.

\section{References}

[2]. Janardan V. Bhatt,. Impact of gender sex on academic examination related stress symptom profile in special reference to sleep among medical students. Indian Journal of Applied Basic Medical Sciences. 2013; 15B (21): 88-94

[3]. Panter-Brick C, Worthman, C.M. Hormones, Health, and Behavior: A socio- ecological and lifespan perspective. 1999. Cambridge University Press.

[4]. Greenberg, J. Comprehensive stress management. 2009. New York: McGraw-Hill Co. 11th edn.

[5]. Murphy, L., Denis, R., Ward, C., Tartar, J. Academic stress differentially influences perceived stress, cortisol, and immune functioning. Stress. Stress. 2010 Jul;13(4):365-70

[6]. Rickertand P, Graeme. WSM-III List learning test and the auditory verbal learning test: comparisons and Australian normative data. Poster Presentation at the 4th annual Conference of the College of Clinical Neuropsychologists. Lorne, Victoria, Australia. (1998).

[7]. PremaSembulingam, Sembulingam K, Namasivayam A. Evaluation of autonomic status in generalized anxiety disorder patients. Biomedicine 2000; 20(2):109-121.

[8]. Kharche JS, Pranita A, Phadke AV, Joshi AR .Evaluation Of Examination Stress in I MBBS Medical Students. NJIRM. 2012;3(5): 27- 31

[9]. Malathi A, Vidya G, Parulkar. Evaluation of Anxiety Status In Medical Students Prior To Examination Stress. Indian J. Physiol. Pharmacol.1992; 36(2): 121-122.

[10]. Rachit M Joshi, Saurin J Sanghavi, Devanshi P Upadhyaya, Ashutoshchauhan, ShitalHalvadia. Effect of examination stress on the plasma cortisol level. National Journal of Medical Research.2012; 2(4):434-438

[11]. McEwen BS, Sapolsky RM. 1995. Stress and cognitive function.CurrOpinNeurobiol 5:205-216

[12]. Sembulingam K and PremaSembulingam, "Essentials of Medical Physiology" $6^{\text {th }}$ edition, 2012. Published by JAYPEE Brothers Medical Publishers (P) Ltd New Delhi. P939).

[13]. Martin B. Anxiety and neurotic disorders.John Wiley and Sons, Inc. New York. 1971; 21-34)

[14]. Velasco M, Gómez J, Blanco M, Rodriguez I. The cold pressor test: pharmacological and therapeutic aspects. Am. J. Ther.1997 Jan; 4(1): 34-8. 
[15]. SaheraShabnam S, GopathySridevi, PremaSembulingam. Gender differences in autonomic functional status in response to stress.Int J Med Res Health Sci. 2013;2(4):737-744. DOI: 10.5958/j.2319-5886.2.4.118)

[16]. Convertio VA. Gender differences in autonomic functions associated with blood pressure regulation. American Journal of Physiology: 1909;20:8).

[17]. Jones PP, Snitker S, Skinner JS, Ravussin E. Gender differences in muscle sympathetic nerve activity: effect of body fat distribution American Journal of Physiology.1996; $270: 363-66$ ). 